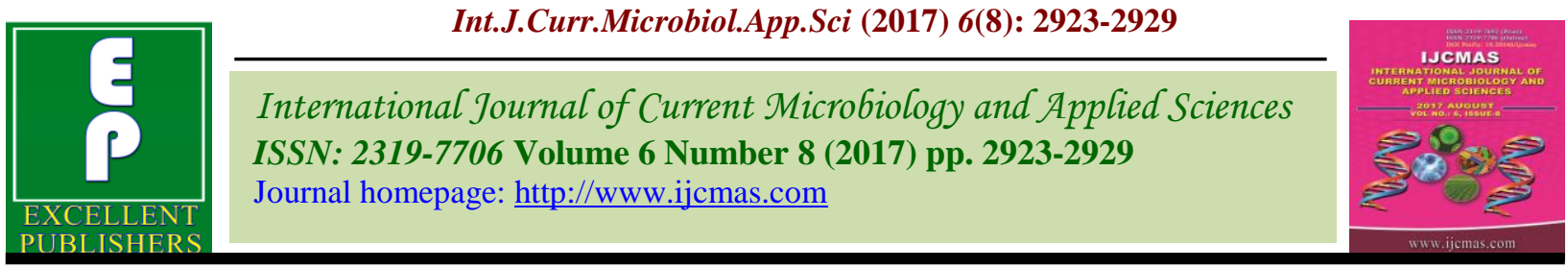

Original Research Article

https://doi.org/10.20546/ijcmas.2017.608.350

\title{
Effect of Packaging and Sodium Bi-carbonate on Storage Life and Quality of Kinnow Fruits
}

\author{
S.K. Jawandha and Kirandeep Kaur* \\ Department of Fruit Science, Punjab Agricultural University, Ludhiana -141004, Punjab, India \\ *Corresponding author
}

\section{A B S T R A C T}

Kinnow (Citrus nobilis $\times$ Citrus deliciosa) fruits harvested at full color

Keywords

Kinnow, Storage,

Packaging,

Spoilage, Sodium

bicarbonate.

Article Info

Accepted:

23 June 2017

Available Online:

10 August 2017 development and maturity were treated with sodium bicarbonate@1\%,2\% and $3 \%$ and packed in shrink film tray packages. These packages were stored at $5-6^{\circ} \mathrm{C}$ and $90-95 \% \mathrm{RH}$ for 90 days and the fruits were analyzed for various physicochemical characteristics after 15, 30, 45, 60,75 and 90 days of cold storage. Sodium bicarbonate @ 2 and 3\% along with shrink film tray packaging significantly reduced the physiological loss in weight and spoilage as compared to the other treatments. The highest total soluble solids, acidity, ascorbic acid content and palatability rating was also recorded with sodium bicarbonate @ 2 and 3\% along with shrink film tray packaging. Thus, the treatment proved quite effective in prolonging the shelf life and maintaining the quality of Kinnow fruits for 75 days while retaining an excellent quality during storage.

\section{Introduction}

Kinnow mandarin (Citrus nobilis $\times$ Citrus deliciosa) is the dominant fruit crop of Punjab and ranks first with respect to area and production. A glut-like situation arises in the major wholesale markets of India because the entire kinnow crop is harvested from December to January and the tree starts flowering in February. The postharvest technologies which can extendits shelf-life could have a profound effect on marketing of Kinnow fruits. The use of sodium salts to reduce postharvest decay especially in citrus fruits has recently received attention. These salts serve as a useful tool to manage citrus postharvest decays due to its considerable antimicrobial activity; it is inexpensive, readily available and can be used with a minimal risk of injury to the fruit (Usall et al., 2008). Sodium bicarbonate has been generally reported as safe (GRAS) by the United States Food and Drug Administration and it is widely used in the food industry to enhance biological control agents efficiency (Mari et al., 2007; Janisiewicz et al., 2008; Geng et al., 2011). Shrink film tray packaging is the latest trend in fresh produce packaging. Besides controlling moisture loss shrink film tray packaging have other beneficial effects like maintenance of firmness, reduction in deformation, alleviation of chilling injury, reduction of decay from secondary infection, delay in colour development and senescence. 
Packing of fruits in polymeric films creates modified atmospheric conditions around the produce inside the package resulting in reduced rate of respiration, transpiration and other metabolic processes of fruits (Lange 2000) thereby allowing lower physiological weight loss, reducing decay incidence and maintaining retention of colour and texture of fruits during extended shelf life (Sharma et al., 2010). Shrink film improved the shelf life and maintained the quality of kinnow fruits for 20 days under supermarket conditions as against 10 days only in case of unpacked control fruits (Mahajan and Singh 2014).Thus, the present study was conducted to study the effect of sodium salts and shrink film tray packaging on extending the shelf life and quality of Kinnow fruits at low temperature storage.

\section{Materials and Methods}

The Kinnow fruits which had attained proper size and color were harvested from New Orchard, Punjab Agricultural University, Ludhiana in the month of January. The fruits were packed in plastic crates and brought to the laboratory. The bruised and diseased fruits were sorted out and only healthy and uniformsized fruits were selected. Washed and uniform sized kinnow fruits were treated with aqueous solutions of sodium bicarbonate (1\%, $2 \%$ and $3 \%$ ) for 5 minutes then air dried and subjected to different treatments. viz., T1 Sodium bicarbonate $1 \%+$ shrink film tray packaging, T2 - Sodium bicarbonate $2 \%+$ shrink film tray packaging, T3 - Sodium bicarbonate $3 \%$ + shrink film tray packaging, T7 - Shrink film tray packaging and T5 Control. For Shrink film tray packaging, six cell paper moulded tray $(220 \mathrm{~mm} \times 140 \mathrm{~mm}$ and $3.15 \mathrm{~mm}$ thick) was used to hold the fruits in the orientation to make a pack. In each tray six fruits of 70-72 mm diameter size were packed. The traypacks were wrapped in cryovac heat shrinkable RD-106 film $(15 \mu)$ and sealed using hot wire sealer. This pack was then passed through shrink packing machine preheated to $165^{\circ} \mathrm{C}$ at a set speed for $10 \mathrm{sec}$ residence time. Thereafter, the packed fruits as well as the control (non-packed) fruits were stored in walk in cool chambers at $5-6^{\circ} \mathrm{C}$ with $90-95 \% \mathrm{RH}$ for 90 days. The observations for various physical and biochemical parameters were recorded at 15 days interval up to 90 days of storage. The physiological loss in weight (PLW) was calculated on initial weight basis. The firmness of the fruit was measured with hand held penetrometer (Model FT-327, Italy) made in Italy and supplied by Elixir Technologies, Bangalore having plunger diameter of $8 \mathrm{~mm}$, and expressed in terms of $\mathrm{kg} / \mathrm{cm}^{2}$. The total soluble solids (TSS) were recorded with hand held refractometer (Erma, Japan), calibrated at $20^{\circ} \mathrm{C}$.

The readings were corrected at $20^{\circ} \mathrm{C}$ and expressed as percentage soluble solids. Juice percentage was calculated by dividing the juice content (ml) and fruit weight $(\mathrm{gm})$ and then multiplying the resultant with 100 . The fruits were estimated for palatability rating by a panel of 3 judges on the basis of general appearance, taste and flavor using Hedonicscale (1-9) described by Amerine et al., (1965) as: 9 (Extremely desirable), 8 (Very much desirable), 7 (Moderately desirable), 6 (Slightly desirable), 5 (Neither desirable nor undesirable), 4 (Slightly undesirable), 3 (Moderately undesirable), 2 (Very much undesirable), 1 (Extremely undesirable). The spoilage per cent of fruits was calculated by counting the spoiled fruits and total number of fruits in each replication of each treatment. The titratable acidity in juice as malic acid was determined by titrating a known volume of juice with $0.1 \mathrm{~N}$ $\mathrm{NaOH}$ using phenolphthalein as an indicator. The total sugars and vitamin-C were estimated as per standard procedures (AOAC 2005). 


\section{Statistical analysis}

Analysis of variance (ANOVA) and the test of mean comparison according to critical difference (CD) were applied. Significance level was accepted at $p \leq 0.05$. The data of 3 replications was analyzed statistically by Factorial analysis in a randomized block design using CPCS1 software as a statistical analysis tool (Cheema and Singh 1993).

\section{Results and Discussion}

\section{Weight loss}

Physiological loss in weight of the fruits increased significantly in all the treatments as the storage period progressed. However, minimum loss in weight $(0.62 \%)$ was found in fruits subjected to sodium bicarbonate@ $3 \%$ and packed in shrink film tray packs closely followed by sodium bicarbonate@ 2\% and packed in shrink film tray packs $(0.67 \%)$ after two months of cold storage (Table 1) while the control fruits, on the other hand, recorded the highest PLW (8.94\%) after the same storage interval. Shrink film tray packaging of fruits alone also showed significantly reduced physiological loss in weight as compared to the control fruits. The highest weight loss in unpacked control fruit might be due to exposure of fruit surface to the open atmosphere resulting in a higher rate of transpiration and respiration thereby leading to a higher weight loss. The most noticeable input of film wrapping was the high reduction of weight loss and the maintenance of fruit freshness over storage (Ben-Yehoshua et al., 1983; D'Aquino et al., 2001).

\section{Spoilage}

Spoilage started appearing after 45 days of storage to the level of only 1.07 per cent (Table 2). Further, the spoilage increased significantly with the prolongation of storage period and maximum spoilage to the tune of $16.28 \%$ was observed in control fruits after 90 days of storage. On the other hand, minimum spoilage was observed in fruits of treatment $\mathrm{T}_{3}(2.42 \%)$ closely followed by $\mathrm{T}_{2}(2.57 \%)$. The combination of sodium bicarbonate and shrink film tray packaging, recorded lower spoilage as compared to shrink film tray packaging alone. The continuous process of transpiration and respiration results in cellular disintegration due to reduced synthesis of protein and nucleic acids which enhances the senescence and spoilage of fruits.

The physical barrier provided by the film prevents the contact of adjacent decayed fruit avoiding secondary infections (D'Aquino et al., 2017). Bicarbonate salts offers some degree of protection against postharvest pathogens of citrus fruit (Palou et al., 2008; Youssef et al., 2012) as a consequence of which, the fruit gets less susceptible to fungal invasion and helps in controlling the postharvest decay of citrus fruits.

\section{Organoleptic quality}

The fruits dipped in $3 \%$ and $2 \%$ sodium bicarbonate solution and packed in shrink film tray packaging showed a gradual and steady increase in the organoleptic quality attributes up to 45 days, after which a gradual decline was observed; whereas in control fruits, the palatability score increased up to 30 days of storage and thereafter declined at a faster pace (Table 3).

The highest organoleptic rating (8.52) was recorded in shrink film tray packed fruits treated with $3 \%$ sodium bicarbonate after 45 days of storage while the lowest score (3.17) was displayed in control fruits after 90 days of storage. The higher palatability rating in film packed fruit might be attributed to the reduction in fruit ripening and softening 
processes that led to the development of better flavor and texture as compared to control. Ladaniya and Singh (2001) also reported better palatability rating in shrink-wrapped citrus fruits than the control ones. The excessive transpiration of unwrapped fruit led to a reduction in fruit size and a rapid loss of firmness which is shown by the increase in deformation of the fruit (Cohen et al., 1990; D'Aquino et al., 2001). The shrink film tray packaging combined with sodium bicarbonate, significantly improved general appearance without affecting other quality parameters as compared to the control fruit throughout the storage period. Sodium bicarbonate when used in postharvest treatments reduced natural decay development of mandarin fruit and did not impair the quality parameters of fruit Hong et al.,, 2014; Youssef et al., 2012).

Table.1 Effect of different treatments on physiological loss in weight (\%) of Kinnow fruits during cold storage

\begin{tabular}{ccccccc}
\hline Treatments & \multicolumn{9}{c}{ Storage intervals } \\
\cline { 2 - 6 } T1 & 15 Days & 30Days & 45 Days & 60 Days & 75 Days & 90 Days \\
T2 & 0.15 & 0.30 & 0.81 & 1.14 & 2.35 & 3.52 \\
T3 & 0.12 & 0.24 & 0.55 & 0.67 & 0.76 & 1.39 \\
T4 & 0.11 & 0.22 & 0.51 & 0.62 & 0.70 & 1.21 \\
T5 & 0.25 & 0.35 & 0.62 & 2.74 & 4.21 & 7.26 \\
\hline
\end{tabular}

C.D. at 5\% Storage interval $=0.004$, Treatment $=0.007$, Storage interval $\mathrm{x}$ Treatment $=0.02$

T1: Sodium bicarbonate-1\% + Shrink film Tray Packaging, T2: Sodium bicarbonate-2\% + Shrink film Tray Packaging, T3: Sodium bicarbonate-3\% + Shrink film Tray Packaging, T4: Shrink film tray packaging, T5: Control

Table.2 Effect of different treatments on spoilage (\%) of Kinnow fruits during cold storage

\begin{tabular}{ccccccc}
\hline Treatments & \multicolumn{7}{c}{ Storage intervals } \\
\cline { 2 - 6 } & 15 Days & 30Days & 45 Days & 60 Days & 75 Days & 90 Days \\
T1 & 0.00 & 0.00 & 1.25 & 3.88 & 5.69 & 8.43 \\
T2 & 0.00 & 0.00 & 0.00 & 3.26 & 4.07 & 8.19 \\
T3 & 0.00 & 0.00 & 0.00 & 2.54 & 4.66 & 7.45 \\
T4 & 0.00 & 0.00 & 3.25 & 6.83 & 9.22 & 13.94 \\
T5 & 0.00 & 0.00 & 5.81 & 9.02 & 13.84 & 16.28 \\
\hline
\end{tabular}

C.D. at 5\% Storage interval $=0.004$, Treatment $=0.002$, Storage interval $\mathrm{x}$ Treatment $=0.01$

T1: Sodium bicarbonate-1\% + Shrink film Tray Packaging, T2: Sodium bicarbonate-2\% + Shrink film Tray Packaging, T3: Sodium bicarbonate-3\% + Shrink film Tray Packaging, T4: Shrink film tray packaging, T5: Control

Table.3 Effect of different treatments on palatability rating (1-9 Hedonic scale) of Kinnow fruits during cold storage

\begin{tabular}{ccccccc}
\hline Treatments & \multicolumn{7}{c}{ Storage intervals } \\
\cline { 2 - 6 } & 15 Days & 30Days & 45 Days & 60 Days & 75 Days & 90 Days \\
T1 & 8.15 & 8.28 & 8.35 & 7.85 & 7.00 & 5.86 \\
T2 & 8.22 & 8.36 & 8.48 & 8.10 & 7.52 & 6.54 \\
T3 & 8.39 & 8.47 & 8.52 & 8.15 & 7.60 & 6.63 \\
T4 & 8.08 & 8.25 & 8.02 & 7.56 & 5.80 & 4.58 \\
T5 & 7.97 & 8.16 & 7.50 & 6.50 & 4.79 & 3.17 \\
\hline
\end{tabular}

C.D. at $5 \% \quad$ Storage interval $=0.004$, Treatment $=0.006$, Storage interval $\mathrm{x}$ Treatment $=0.01$

T1: Sodium bicarbonate-1\% + Shrink film Tray Packaging, T2: Sodium bicarbonate-2\% + Shrink film Tray Packaging, T3: Sodium bicarbonate-3\% + Shrink film Tray Packaging, T4: Shrink film tray packaging, T5: Control 
Table.4 Effect of different treatments on total soluble solids (\%) of Kinnow fruits during cold storage

\begin{tabular}{ccccccc}
\hline Treatments & \multicolumn{7}{c}{ Storage intervals } \\
\cline { 2 - 6 } & 15 Days & 30Days & 45 Days & 60 Days & 75 Days & 90 Days \\
T1 & 11.05 & 11.37 & 12.53 & 12.56 & 11.74 & 10.65 \\
T2 & 10.78 & 11.22 & 12.82 & 12.84 & 11.88 & 11.34 \\
T3 & 10.69 & 11.18 & 12.87 & 12.88 & 12.04 & 11.52 \\
T4 & 11.54 & 11.85 & 12.14 & 12.20 & 11.16 & 8.89 \\
T5 & 11.60 & 12.45 & 11.85 & 11.64 & 9.83 & 7.12 \\
\hline
\end{tabular}

C.D. at $5 \% \quad$ Storage interval $=0.005$, Treatment $=0.008$, Storage interval $\mathrm{x}$ Treatment $=0.02$

T1: Sodium bicarbonate-1\% + Shrink film Tray Packaging, T2: Sodium bicarbonate-2\% + Shrink film Tray Packaging, T3: Sodium bicarbonate-3\% + Shrink film Tray Packaging, T4: Shrink film tray packaging, T5: Control

Table.5 Effect of different treatments on acidity (\%) of Kinnow fruits during cold storage

\begin{tabular}{ccccccc}
\hline Treatments & \multicolumn{6}{c}{ Storage intervals } \\
\cline { 2 - 6 } & 15 Days & 30Days & 45 Days & 60 Days & 75 Days & 90 Days \\
T1 & 0.72 & 0.69 & 0.64 & 0.61 & 0.54 & 0.50 \\
T2 & 0.74 & 0.71 & 0.67 & 0.63 & 0.57 & 0.54 \\
T3 & 0.79 & 0.76 & 0.72 & 0.68 & 0.61 & 0.57 \\
T4 & 0.68 & 0.64 & 0.58 & 0.54 & 0.50 & 0.46 \\
T5 & 0.63 & 0.59 & 0.54 & 0.51 & 0.48 & 0.42 \\
\hline C.D. at 5\% & \multicolumn{5}{c}{ Storage interval $=0.004$} & Treatment $=0.007$, Storage interval x Treatment $=0.02$
\end{tabular}

T1: Sodium bicarbonate-1\% + Shrink film Tray Packaging, T2: Sodium bicarbonate-2\% + Shrink film Tray Packaging, T3: Sodium bicarbonate-3\% + Shrink film Tray Packaging, T4: Shrink film tray packaging, T5: Control

Table.6 Effect of different treatments on vitamin C (mg/100ml) of Kinnow fruits during cold storage

\begin{tabular}{ccccccc}
\hline Treatments & \multicolumn{5}{c}{ Storage intervals } \\
\cline { 2 - 6 } & 15 Days & 30Days & 45 Days & 60 Days & 75 Days & 90 Days \\
T1 & 24.78 & 24.10 & 22.84 & 21.78 & 20.26 & 12.74 \\
T2 & 24.94 & 24.45 & 23.80 & 23.35 & 22.54 & 13.11 \\
T3 & 25.12 & 24.82 & 24.20 & 23.78 & 23.11 & 13.42 \\
T4 & 24.44 & 23.02 & 21.86 & 20.92 & 19.80 & 11.64 \\
T5 & 22.25 & 21.14 & 19.80 & 16.08 & 12.88 & 10.66 \\
\hline C.D. at 5\% & \multicolumn{2}{c}{ Storage interval $=0.004$, Treatment $=0.002$, Storage interval x Treatment $=0.01$}
\end{tabular}

T1: Sodium bicarbonate-1\% + Shrink film Tray Packaging, T2: Sodium bicarbonate-2\% + Shrink film Tray Packaging, T3: Sodium bicarbonate-3\% + Shrink film Tray Packaging, T4: Shrink film tray packaging, T5: Control

\section{Total soluble solids}

The total soluble solids continued to increase with the progressive increase (Table 4) in storage intervals up to 60 days and reached to peak value of $12.88 \%$ in fruits packed in shrink film trays with $3 \%$ sodium bicarbonate treatment and then declined thereafter. The control fruits registered a peak value after 30 days of storage (12.442\%) and then declined at a faster pace afterwards. This increase in total soluble solids with an increase in the storage interval might be due to increased hydrolysis of polysaccharides and concentration of juice due to dehydration. The delayed increase in TSS of kinnow fruits packed in shrink film trays with $3 \%$ sodium bicarbonate might be attributed to delayed ripening and senescence processes. Mahajan and Singh (2014) reported a delayed and 
sustained increase in the total soluble solids in shrink-film-packed kinnow fruits.

\section{Acidity}

The acidity showed a linear declining trend with advancement of storage period but did not varied significantly among the different treatments (Table 5). However, the fruits treated with $3 \%$ sodium bicarbonate and packed in shrink film tray packaging maintained the highest acidity content from $(0.79 \%$ to $0.57 \%)$ while the lowest acidity content $(0.63 \%$ to $0.42 \%)$ was recorded in control fruits from the start to the end of the stipulated storage period. The progressive reduction in the acidity with advancement of storage period might be due to acidic hydrolysis of polysaccharides where acid is utilized for converting non-reducing sugars into reducing sugars (Bhardwaj and Pandey 2011). The packaging films helped in better retention of acidity as compared to control. In wrapped fruits, the lowering of acidity was delayed, which might be due to the effect of packaging films in delaying the respiratory and ripening process.

\section{Ascorbic acid}

A continuous decline in vitamin $\mathrm{C}$ content in Kinnow fruits was noticed with advancement of storage period irrespective of different packaging films (Table 6). The maximum average vitamin $\mathrm{C}$ content $(18.6 \mathrm{mg} \%)$ was observed with shrink film packaging. The control fruits recorded the minimum average vitamin $\mathrm{C}$ content (15.8 $\mathrm{mg} \%)$. The decrease in ascorbic acid during storage may be due to the oxidation of L-ascorbic acid into dehydroascorbic acid (Mapson 1970). The influence of heat-shrinkable films on maintaining higher ascorbic acid content in sweet orange had also been reported (Ladaniya and Singh, 2001). Various reports had shown that vitamin $\mathrm{C}$ decreased under ambient and refrigerated conditions during storage of citrus fruit such as blood orange, sweet orange and mandarin (Rapisarda et al., 2001).

In conclusion, the treatment of kinnow fruits with aqueous solutions of sodium bicarbonate@3\% and sodium bicarbonate@2\% along with shrink film tray packaging can prolong the storage life of kinnow fruits up to 75 days with minimum weight loss, acceptable firmness, and desirable quality.

\section{References}

Amerine, M.A., Pangborn, R.M. and Roessler, E.B. 1965. Principles of sensory evaluation of food. Academic Press, London.

Association of Official Analytical Chemists A.O.A.C. 2005. Official and tentative methods of analytical chemists, $17^{\text {th }} \mathrm{ed}$. AOAC, Washington, DC.

Bhardwaj, R.L. and Pandey, S. 2011.Juice blends--a way of utilization of underutilized fruits, vegetables, and spices: a review. Crit Rev Food SciNutr. 51(6):563-70.

Mahajan, B.V.C. and Singh, R. 2014. Effect of packaging films on shelf life and quality of kinnow fruits packed in consumer packages. International Journal of Farm Sciences4(1):92-98.

Cheema, H.S. and Singh, B. 1993. CPCS 1: Aprogramme package for the analysis of commonly used experimental designs. Punjab Agricultural University, Ludhiana

Hong, P., Hao, W., Luo, J., Chen, S., Guohua, M. Huand Zhong 2014. Combination of hot water, Bacillus amyloliquefaciens HF-01 and sodium bicarbonate treatments to control postharvest decay of mandarin fruit. Postharvest Biol and Technol88: 96-102. 
Palou, L., Smilanick, J.L. and Droby, S. 2008. Alternatives to conventional fungicides for the control of citrus postharvest green and blue moulds. Stewart Postharvest Rev., 2: 2-16.

Ladaniya, M.S. and Singh, S. 2001. Tray over-wrapping of Mosambi sweet orange. J Food Science and Technol38: 362-365.

Lange, D.L. 2000. New film technologies for horticultural products. Horticultural Technology 10: 487-490.

Mapson, C.W. 1970. Vitamins in Fruits: Stability of L-Ascorbic Acid in Biochemistry of Fruits and their Products, pp. 376-387, Academic Press, London.

Geng, S.H., Chen, M.Y.Hu, Muhammad,R., Lai,K.P., Qu,F. and Zhang,Y.B.2011.Combination of Kluyveromycesmarxianus and sodium bicarbonate for controlling green mold of citrus fruit. Int J Food Microbiol, 151: 190-194.

Rapisarda, P., Bellomo, S.E. and Intelisano, S. 2001. Storage temperature effects on blood orange fruit quality. Journal of Agricultural and Food Chemistry, 49: 3230-3235.

Ben-Yehoshua, S., Shapiro, B.M., EvenChen,Z. and Lurie,S.1983. Mode of action of plastic film extending life of lemon and bell pepper fruit by alleviation of water stress Plant Physiol, 73: 87-93.

D'Aquino, S., Angioni, M., Schirru, S., and Agabbio, M.2001. Quality and physiological changes of film packaged malvasio mandarins during long term storage. Food Sci Technol, 34: 206214.

D’Aquino, S., Suming, D., Deng, Z., Gentile, A., Angioni, A., De PauL., and Palma, A. 2017. A sequential treatment with sodium hypochlorite and a reduced dose of imazalil heated at $50{ }^{\circ} \mathrm{C}$ effectively control decay of individually filmwrapped lemons stored at $20^{\circ} \mathrm{C}$. Postharvest Biol and Technol124: 7584.

Sharma, R.R., Pal, R.K., Singh, D., Samuel, D.V.K., Kar, A. and Asrey, R. 2010. Storage life and fruit quality of individually shrink-wrapped apples (Malusdomestica) in zero energy cool chamber. Indian Journal of Agriculture Science 80(4): 338-341.

Usall, J., Smilanick, J., Palou, L., DenisArrue, N., Teixido, N., Torres, R. and Vinas,I. 2008. Preventive and curative activity of combined treatments of sodium carbonates and Pantoeaagglomerans CPA-2 to control postharvest green mold of citrus fruit. Postharvest BiolTechnol, 50: 1-7.

Janisiewicz, W.J., Saftner, R.A., William, S.C. and Yoder, K.S. 2008. Control of blue mold decay of apple during commercial controlled atmosphere storage with yeast antagonists and sodium bicarbonate. Postharvest Biol Technol, 49: 374-378.

Youssef, K., Ligorio, A., Sanzani, S.M., Nigro, F. and Ippolito, A. 2012. Control of storage diseases of citrus by pre- and postharvest application of salts. Postharvest BiolTechnol72, 57-63.

\section{How to cite this article:}

Jawandha, S.K. and Kirandeep Kaur. 2017. Effect of Packaging and Sodium Bi-carbonate on Storage Life and Quality of Kinnow Fruits. Int.J.Curr.Microbiol.App.Sci. 6(8): 2923-2929. doi: https://doi.org/10.20546/ijcmas.2017.608.350 